\title{
Prediction of periodontopathic bacteria in dental plaque of periodontal healthy subjects by measurement of volatile sulfur compounds in mouth air
}

Mitsuo Kishi ${ }^{\mathrm{a} *}$, Yuko Ohara-Nemoto ${ }^{\mathrm{b}}$, Masahiro Takahashi ${ }^{\mathrm{a}}$, Kayo Kishi ${ }^{\mathrm{c}}$, Shigenobu Kimura $^{\mathrm{b}}$, Fumie Aizawa ${ }^{\mathrm{a}}$, and Masami Yonemitsu ${ }^{\mathrm{a}}$

${ }^{\mathrm{a}}$ Department of Developmental Oral Health Science, Division of Oral Health, Iwate Medical University School of Dentistry, Morioka, Japan

${ }^{\mathrm{b}}$ Department of Oral Molecular Biology, Course of Medical and Dental Sciences, Nagasaki University Graduate School of Biomedical Sciences, Nagasaki, Japan

${ }^{c}$ Department of Microbiology, Division of Molecular Microbiology, Iwate Medical University, Yahaba, Iwate, Japan

Running title: Prediction of periodontal bacteria by VSC measurement

Key words: volatile sulfur compound, periodontopathic bacteria, dental plaque, tongue coating, oral malodor, polymerase chain reaction

*Corresponding author: Mitsuo Kishi

Department of Preventive Dentistry, School of Dentistry, Iwate Medical University 1-3-27 Chuo-dori, Morioka 020-8505, Japan

+81-19-653-5111 (Phone), +81-19-622-2228 (FAX), mkishi@iwate-med.ac.jp (E-mail) 


\section{ABSTRACT}

Objectives: The aim of this study was to determine whether measurements of volatile sulfur compounds (VSCs) are useful to predict colonization of periodontopathic bacteria. For this purpose, we assessed the relationships among distributions of 4 species of periodontopathic bacteria in tongue coating and dental plaque, oral conditions including VSC concentration in mouth air, and smoking habit of periodontal healthy young subjects.

Methods: The subjects were 108 young adults (mean age, $23.5 \pm 2.56$ years) without clinical periodontal pockets. Information regarding smoking habit was obtained by interview. After VSC concentration in mouth air was measured with a portable sulfide monitor (Halimeter ${ }^{\circledR}$ ), non-stimulated saliva flow and dental caries status were assessed, and tongue coating and dental plaque samples were collected from the subjects. The tongue coating samples were weighed to determine the amount. The colonization of Porphyromonas gingivalis, Tannerella forsythia, Prevotella intermedia, and Treponema denticola in both tongue coating and plaque samples was investigated using species-specific polymerase chain reaction assays.

Results: Significant relationships were observed between the colonization of periodontopathic bacteria in tongue coating and plaque samples, especially that of $P$. gingivalis. VSC concentration showed the most significant association with colonization of P. gingivalis in both tongue coating and dental plaque. Logistic regression analysis demonstrated that the adjusted partial correlation coefficient $[\operatorname{Exp}(B)]$ values for VSC concentration with the colonization of P. gingivalis, $P$. intermedia, and T. denticola in dental plaque were 135, 35.4 and 10.4, respectively. In addition, smoking habit was also shown to 
be a significant variable in regression models $[\operatorname{Exp}(B)=6.19,8.92$, and 2.53, respectively]. Therefore, receiver operating characteristic analysis was performed to predict the colonization of periodontal bacteria in dental plaque in the subjects divided by smoking habit. Based on our results, we found cut-off values that indicated likelihood ratios (LR) within the efficient range for positive findings in both groups.

Conclusion: The present results demonstrated that measurement of VSC concentration in mouth air is a useful method to predict the presence of colonization of some periodontopathic bacteria in dental plaque. 


\section{INTRODUCTION}

Some periodontopathic bacteria, e.g., Porphyromonas gingivalis, Prevotella intermedia, Tannerella forsythia, and Treponema denticola, are highly capable of producing volatile sulfur compounds (VSC), which are considered to be a primary cause of oral malodor. $^{1-5}$ In some studies, high levels of VSC in mouth air have been occasionally found in periodontal healthy individuals. ${ }^{6,13,14}$ On the other hand, oral malodor has been shown to be significantly related to periodontal status in both clinical and epidemiological studies. ${ }^{6-11}$ Furthermore, recent studies have found a relationship between VSC level in mouth air and VSC-producing periodontopathic bacteria on the tongue. ${ }^{13,15-17}$

Tongue coating has been suggested to be an important reservoir of oral microorganisms for later attachment to tooth surfaces, thus microorganisms harbored on the tongue may contribute to plaque formation, ${ }^{18-22}$ and there may be a relationship between microflora in tongue coating and dental plaque. We speculated that colonization of periodontopathic bacteria not only in tongue coating but also in dental plaque samples could be predicted by measurement of VSC in mouth air. In this study, we examined the prevalence of periodontopathic bacteria in both tongue coating and dental plaque samples obtained from young subjects without clinical periodontal pockets. From the results, we attempted to develop simple prediction models to show colonization of periodontopathic bacteria in dental plaque by measurement of VSC in mouth air.

\section{MATERIALS \& METHODS}

\section{Subjects}


The present subjects were recruited from students attending a dental university and those at a school for dental hygienists. Each provided informed consent according to a protocol approved by the Ethics Committees of Iwate Medical University School of Dentistry (No. 01027) and agreed to participate in the study. To exclude those with periodontitis, oral examinations were carried out, during which a well-trained examiner measured the periodontal pocket depths of all present teeth. At the same time, dental caries status was assessed according to the method of the World Health Organization. ${ }^{23}$ Finally, 108 volunteers (mean 23.5 \pm 2.55 years old; 68 males, 40 females) were enrolled. None had pockets greater than $3 \mathrm{~mm}$ deep or attachment loss at any site in the mouth, and the average number of DMFT was 8.44 \pm 5.42 (range 0 -18). Within 1 week after the oral examination, measurement of VSC concentration in mouth air, assessment of saliva flow amount, and collection of oral specimens were carried out. Prior to the oral examinations, information regarding smoking habit was obtained from each subject by interview, which showed that 47 had a smoking habit and 61 did not, of whom 55 had never smoked and 6 had a previous smoking experience but had stopped. Similarly, it was confirmed that none were suffering from other oral or systemic diseases, nor had received antibiotic medication within 1 month prior to the examination day.

\section{Measurement of VSC concentration}

VSC concentration in mouth air was measured using a portable sulfide monitor (Halimeter ${ }^{\circledR}$ RH-17K; Interscan Corp., Chatsworth, CA, USA). This instrument responds to all 3 volatile sulfur compounds [hydrogen sulfide $\left(\mathrm{H}_{2} \mathrm{~S}\right)$, methyl mercaptan $\left(\mathrm{CH}_{3} \mathrm{SH}\right)$, 
dimethyl sulfide $\left.\left(\mathrm{CH}_{3} \mathrm{SCH}_{3}\right)\right]$, and gives a reading for total VSC concentration. Individual VSC concentration was obtained according to the manufacture's manual, with a slight modification. In brief, the subjects were instructed to refrain from using scented products on the examination day, as well as from such oral activities as smoking, drinking, eating, chewing gum, tooth brushing, and mouth rinsing at least 2 hours before testing. After the subject closed the mouth with breathing through the nose for 2 minutes, a disposable plastic straw attached to the air inlet of the monitor was inserted approximately $4 \mathrm{~cm}$ into the nearly closed mouth. The maximum value of 3 separate measurements was used as the individual VSC concentration. VSC concentrations were transformed to logarithms (logVSC) for further analysis.

\section{Assessment of saliva flow amount}

For assessing saliva-flow amount, the subjects were instructed to deposit non-stimulated saliva into a plastic tube for a period of 5 minutes, after which the volume of accumulated saliva was measured.

\section{Collection of tongue coating and plaque samples}

Tongue coating samples were collected as previously reported. ${ }^{6,13}$ Briefly, after removing saliva from the tongue dorsum with cotton and a stream of air, any tongue accretion between the lingual papillae was removed carefully from the circumvallate papilla to the apex of the tongue dorsum by scratching with a sterile toothbrush. Collected samples were immersed in sterile phosphate-buffered saline (PBS; $\mathrm{pH} 7.4$ ) and dispersed 
by sonication on ice. After centrifugation and washing with PBS for 3 times, we determined the amount of each tongue coating sample by measuring absorbance of the dispersed suspension sample with a calibration curve, which was obtained in a preliminary examination. $^{22}$ Dental plaque samples were taken with a sterile dental probe from the lingual surfaces of first or second molars of both sides. Collected plaque samples were similarly immersed in PBS and washed 3 times.

\section{PCR analysis}

Bacterial genomic DNA was purified from $4 \mathrm{mg}$ of each tongue coating sample as well as from the whole quantity of each plaque sample using a Wizard Genomic DNA Purification Kit (Promega Co., Madison, USA), according to the manufacturer's instructions. As a positive control, 16S rRNA genes were amplified with a universal primer as well as species-specific primers. Positive and negative controls were included in all sample-processing procedures for each primer. The target bacteria were 4 periodontopathic species; P. gingivalis, P. intermedia, T. forsythia, and T. denticola, and 16S rRNA-based PCR assays were performed using species-specific PCR primers, as reported previously (Table 1). ${ }^{22,24}$ The bacterium-specific primer $\left(5-3^{\prime}\right)$ sequences used in this study were as follows: $P$. gingivalis, sense, 5 -TGTAGATGACTGATGGTGAAAACC-3', and antisense, 5'-ACGTCATCCCCACCTTCCTC-3' (PCR product size $197 \mathrm{bp}$ ); T. forsythia, sense, 5'-GCGTATGTAACCTGCCCGCA-3', and antisense, 5'-TGCTTCAGTGTCAGTTATACCT-3' (311 bp); $P . \quad$ intermedia, sense, 5'-TTTGTTGGGGAGAAAGCGGG-3', and antisense, 5'- 
TCAACATCTCTGTATCCTGCG-3' 5'-AAGGCGGTAGAGCCGCTCA-3', bp); T. denticola, sense, and antisense,

5'-AGCCGCTGTCGAAAAGCCCA-3' (575 bp).

The amplification was performed as follows: P. gingivalis, $95^{\circ} \mathrm{C}$ for $15 \mathrm{~min}$, followed by 30 cycles at $94^{\circ} \mathrm{C}$ for $0.5 \mathrm{~min}, 58^{\circ} \mathrm{C}$ for $0.5 \mathrm{~min}$, and $72^{\circ} \mathrm{C}$ for $0.5 \mathrm{~min}$, with a final elongation at $72^{\circ} \mathrm{C}$ for $4 \mathrm{~min}$; T. forsythia and T. denticola, $95^{\circ} \mathrm{C}$ for $15 \mathrm{~min}$, followed by 30 cycles at $94^{\circ} \mathrm{C}$ for $0.5 \mathrm{~min}, 60^{\circ} \mathrm{C}$ for $0.5 \mathrm{~min}$, and $72^{\circ} \mathrm{C}$ for $0.5 \mathrm{~min}$, with a final elongation at $72{ }^{\circ} \mathrm{C}$ for $4 \mathrm{~min}$; P. intermedia, $95^{\circ} \mathrm{C}$ for $15 \mathrm{~min}$, followed by 35 cycles at $94^{\circ} \mathrm{C}$ for $0.5 \mathrm{~min}, 60^{\circ} \mathrm{C}$ for $0.5 \mathrm{~min}$, and $72^{\circ} \mathrm{C}$ for $0.5 \mathrm{~min}$, with a final elongation at $72^{\circ} \mathrm{C}$ for $4 \mathrm{~min}$. The PCR amplification products were then examined by electrophoresis in 1.8\% agarose gel-Tris-borate-EDTA buffer. Amplified DNA was stained with ethidium bromide and visualized under UV illumination.

\section{Statistical analyses}

The relationships between colonization of each periodontopathic bacterium in the tongue coating and dental plaque samples were examined using a chi-squared test for independence. Multiple tests to assess the relationships of age, gender, smoking habit, and oral status with colonization by each periodontopathic bacterium were examined using logistic regression analysis. Furthermore, receiver operating characteristic (ROC) analysis was used to examine the effectiveness of VSC concentration to predict colonization of periodontopathic bacteria in dental plaque. 


\section{RESULTS}

Distributions of age and measurements among the subjects are summarized in Table 1. The results of periodontopathic bacteria detected in the tongue coating and dental plaque samples in individual subjects were usually in agreement. In cases of disagreement, $P$. gingivalis, $T$. forsythia, and $P$. intermedia were detected more frequently in the tongue coating samples, while T. denticola was detected more often in plaque samples (Table 2). In all subjects, $T$. forsythia was detected most frequently in both tongue coating (84.2\%) and dental plaque (66.7\%) samples, while $T$. denticola (15.7\%) had the lowers rate of detection in the tongue coating samples and $P$. gingivalis $(11.1 \%)$ in the dental plaque samples. In all subjects, the prevalence of $P$. gingivalis, $T$. forsythia, and $P$. intermedia in tongue coating was significantly higher than in dental plaque, while the prevalence of $T$. denticola in tongue coating was significantly lower than in dental plaque.

We assessed the relationships of age, gender, smoking habit, and oral status (amount of tongue coating, salivary volume and number of DMFT) in regard to colonization of each periodontopathic bacterium in the tongue coating and dental plaque samples using logistic regression analysis. In a regression model for bacterial colonization in tongue coating, $\log$ VSC was selected as the most significant variable related to the colonization of $P$. gingivalis and $T$. forsythia, after a stepwise procedure (Table 3). In a regression model for bacterial colonization in dental plaque, logVSC was selected as the most significant variable related to colonization of $P$. gingivalis. Furthermore, a significant relationship of logVSC with colonization in dental plaque was observed for P. intermedia and T. denticola, however, not for $T$. forsythia. In addition, smoking habit was selected as a significant 
variable related to the colonization of $P$. gingivalis, $P$. intermedia, and $T$. denticola in dental plaque. Since smoking habit was a binary variable shown to be related to the colonization of 3 of the tested periodontopathic bacteria, the subjects were subsequently divided into 2 groups for ROC analysis, in which VSC concentration in mouth air was used to identify the presence of those periodontopathic bacteria in dental plaque. Furthermore, we calculated likelihood ratios at all coordinate points on the ROC curve. Consequently, we determined the optimal cut-off value of VSC corresponded with the coordinate point showed maximum likelihood ratio for positive test $[\operatorname{LR}(+)]$ to identify individuals with periodontopathic bacterium in their dental plaque.

Figures 1 to 3 present ROC curves of log VSC values for identifying $P$. gingivalis, $P$. intermedia, and T. denticola in dental plaque of subjects with and without a smoking habit. The optimal cut-off values of VSC and indices of effectiveness for identifying those 3 periodontopathic bacteria in dental plaque are summarized in Table 4. For identification of P. gingivalis in subjects with a smoking habit, use of $230 \mathrm{ppb}$ as a cut-off value resulted in an $\mathrm{LR}(+)$ value 17.1 and likelihood ratio for negative test [LR(-)] value of 1.71 . Furthermore, the post-test probability (0.750) was approximately 5 times higher than the pre-test probability (0.149). These results indicate that VSC concentration is an effective means to identify $P$. gingivalis in dental plaque, whereas a negative result may not exclude the possibility of its presence. In subjects without a smoking habit, the effectiveness of identifying $P$. gingivalis was also demonstrated by a high LR(+) value of 16.8 and a much higher post-test probability (0.600) as compared with pre-test probability (0.082), while the optimal cut-off value was higher (442 ppb) than that for subjects with a smoking habit. The 
effectiveness of positive test results was also demonstrated for identifying $P$. intermedia and $T$. denticola, though the $\operatorname{LR}(+)$ values and ratios of post-test probability to pre-test probability were not high as with $P$. gingivalis identification. Furthermore, lower cut-off values in subjects with a smoking habit as compared to those without a smoking habit were seen, similar to the results with P. gingivalis identification.

\section{DISCUSSION}

In the present study, we demonstrated that colonization in dental plaque by 3 of the 4 studied periodontopathic bacteria can be predicted by measuring VSC concentration in mouth air. Among the tests, $\mathrm{LR}(+)$ had the highest sensitivity for identifying $P$. gingivalis in subjects both with and without a smoking habit (Table 4). In addition, the $\operatorname{LR}(+)$ values in tests used to identify P. intermedia and T. denticola ranged from 5.14 to 8.84. In general, when the $\mathrm{LR}(+)$ value is greater than 5.0 , the test is thought to be contributable for

diagnosis ${ }^{25,26}$ On the other hand, LR(-) was low in the cut-off points of all the examined tests. Thus, VSC concentration in mouth air over the cut-off value in each test can predict the existence of the periodontopathic bacteria in dental plaque with a high probability, while a concentration less than the cut-off value does not decisively indicate the absence of bacteria.

In spite of low LR(-) values resulting in a considerable number of false negative results, the ability to identify periodontopathic bacteria in dental plaque using a simple and noninvasive test, i.e., VSC measurement, is an important finding. Furthermore, this test seems suitable to identify early colonization of periodontopathic bacteria for both diagnosis 
and indication of periodontitis development. However, for practical use, further research with a greater number of subjects is required to obtain more accurate reference and cut-off values.

VSC concentration in mouth air was most related to the colonization of $P$. gingivalis in tongue coating, in agreement with our previous report. ${ }^{13}$ Furthermore, the concordance rate of colonization between tongue coating and dental plaque was highest for $P$. gingivalis among the tested bacteria. Therefore, it is reasonable to speculate that VSC concentration may be significantly related to $P$. gingivalis colonization in both tongue coating and dental plaque. On the other hand, the concordance rates were lower for $P$. intermedia and $T$. denticola, and VSC concentration was related to only their colonization in dental plaque and not in tongue coating. Although the reason was not clarified, negative correlations were shown between the amount of tongue coating and colonization of both $P$. intermedia and $T$. denticola in dental plaque. These findings indicate the high probability of colonization of those bacteria in dental plaque in cases of high VSC concentration in spite of a low amount of tongue coating. In addition to VSC-producing bacteria in deposited tongue coating, which is considered to be a main cause of oral malodor in periodontal healthy individuals, these bacteria in dental plaque may also increase VSC concentration in whole mouth air when the amount of tongue coating is scant. Additionally, we found that VSC concentration was related to the colonization of $T$. forsythia in tongue coating, but not that in dental plaque, while the relationship was weakest, due to its high prevalence.

The present results clearly demonstrated that smoking habit is an important factor for colonization of $P$. gingivalis and $T$. denticola, even in periodontal healthy individuals. 
Colonization of those bacteria was more often indicated with lower VSC concentrations in current smokers as compared with non-smokers. These results are in good agreement with previous studies showing that current smoking habit is a major environmental risk factor for periodontitis, and that smokers are more likely to be infected with $P$. gingivalis or other periodontopathic bacteria. ${ }^{27-31}$ Therefore, using interviews about smoking habit and measurements of VSC, we think that it is possible to predict the colonization of some periodontopathic bacteria in dental plaque of periodontal healthy subjects with considerable accuracy. In addition, the Halimeter ${ }^{\circledR}$, relatively inexpensive and easy to use, is a popular sulfide monitor and widely used by many clinical dentists for oral malodor research. ${ }^{32-35}$

Hence, we propose that VSC measurement is a useful tool for assessing the risks of periodontitis in periodontal healthy young adults.

\section{ACKNOWLEDGEMENTS}

This work was supported in part by grants-in-aid for scientific research from the Ministry of Education, Science, Sports and Culture of Japan (C 17592188), and Open Research Project (2007-2011) from the Ministry of Education, Culture, Sports, Science and Technology of Japan. 


\section{REFERENCES}

1. Tonzetich J, McBride BC. Characterization of volatile sulphur production by pathogenic and non-pathogenic strains of oral Bacteroides. Arch Oral Biol 1981;26(12):963-9.

2. Persson S, Edlund MB, Clarsson J: The formation of hydrogen sulfide and methyl mercaptan by oral bacteria. Oral Microbiol Immunol 1990;5(4): 195-201.

3. Claesson R, Edlund MB, Persson S, Carlsson J: Production of volatile sulfur compounds by various Fusobacterium species. Oral Microbiol. Immunol 1990;5(3): 137-42.

4. Ratcliff PA and Johnson PW: The relationship between oral malodor, gingivitis, and periodontitis. A review. J Periodontol 1999;70(5):485-89.

5. Nakano Y, Yoshimura M and Koga T: Methyl mercaptan production by periodontal bacteria. Int Dent J 2002; 52 (Suppl 3): 217-20.

6. Yaegaki K and Sanada K: Biochemical and clinical factors influencing oral malodor in periodontal patients. J Periodontol 1992;63(9):783-9.

7. Yaegaki $\mathrm{K}$ and Sanada K: Volatile sulfur compounds in mouth air from clinically healthy subjects and patients with disease. J Periodontol Res 1992; 27(4 Pt 1): 233-8.

8. Bosy A, Kulkarni GV, Rosenberg M, McCulloch CA: Relationship of oral malodor to periodontitis: evidence of independence in discrete subpopulations. J Periodontol 1994; 65(1):37-46.

9. De Boever EH, De Uzeda M, Loesche WJ: Relationship between volatile compounds, 
BANA-hydrolyzing bacteria and gingival health in patients with and without complaints of oral malodor. J Clin Dent 1994;4(4):114-9.

10. Morita and Wang: Relationship of sulufide level to severity of periodontal disease and BANA test. J Periodontol 2001;72(1):74-8.

11. Figueiredo LC, Rosetti EP, Marcantonio E Jr, Marcantonio RA, Salvador SL: The relationship of oral malodor in patients with or without periodontal disease. $J$ Periodontol 2002;73(11):1338-42.

12. Miyazaki H, Sakao S, Katoh Y, Takehara T: Correlation between volatile sulphur compounds and certain oral health measurements in the general population. $J$ Periodontol 1995;66(8):679-84.

13. Kishi M, Kimura S, Ohara-Nemoto Y, Kishi K, Aizawa F, Moriya T, Yonemitsu M: Oral malodor and periodontopathic microorganisms in tongue coat of periodontally healthy subjects. Dent Jpn 2002;38(1):24-8.

14. Hinode D, Fukui M, Yokoyama N, Yokoyama M, Yoshioka M, Nakamura R: Relationship between tongue coating and secretory-immunoglobulin A level in saliva obtained from patients complaining of oral malodor. J Clin Periodontol 2003;30(12): 1017-23.

15. Tanaka M, Yamamoto Y, Kuboniwa M, Nonaka A, Nishida N, Maeda K, Kataoka K, Nagata H, Shizukuishi S: Contribution of periodontal pathogens on tongue dorsa analyzed with real-time PCR to oral malodor. Microbes Infect 2004;6(12):1078-83.

16. Washio J, Sato T, Koseki T, Takahashi N: Hydrogen sulfide-producing bacteria in tongue biofilm and their relationship with oral malodour. J Med Microbiol 2005; 54(Pt 
9), 889-895.

17. Kurata H, Awano S, Yoshida A, Ansai T, Takehara: The prevalence of periodontopathogenic bacteria in saliva is linked to periodontal health status and oral malodour. J Med Microbiol 2008;57(Pt 5), 636-42.

18. Van der Velden U, Van Winkelhoff AJ, Abbas F, De Graaff J: The habitat of periodontopathic micro-organisms. J Clin Periodontol 1986;13(3):243-8.

19. Dahlén G, Manji F, Baelum V, Fejerskov O: Putative periodotopathogens in “diseased” and "non-diseased" persons exhibiting poor oral hygiene. J Clin Periodontol 1990;19(1):35-42.

20. Mager DL, Ximenez-Fyvie LA, Haffajee AD, Socransky SS: Distribution of selected bacterial species on intraoral surfaces. J Clin Periodontol 2003;30(7):644-54.

21. Faveri M, Feres M, Shibli JA, Hayacibara RF, Hayacibara MM, de Figueiredo LC: Microbiota of the dorsum of the tongue after plaque accumulation: an experimental study in humans. J Periodontol 2006;77(9):1539-46.

22. Kishi M, Ohara-Nemoto Y, Takahashi M, Kishi K, Kimura S, Yonemitsu M: Relationship between oral status and prevalence of periodontopathic bacteria on tongues of elderly individuals. J Med Microbiol 2010;59 (Pt 11):1354-9.

23. World Health Organization: Oral Health Surveys. Basic Methods. 4th ed. Geneva, World Health Organization, 1997.

24. Kimura S, Ooshima T, Takiguchi M, Sasaki Y, Amano A, Morisaki I, Hamada S: Periodontopathic bacterial infection in childhood. J Periodontol 2002; 73(1):20-6.

25. Jaeschke R, Guyatt GH, Sackett DL: Users' guides to the medical literature. III. How to 
use an article about a diagnostic test. A. Are the results of the study valid? The Evidence-Based Medicine Working Group. JAMA 1994;271(5):389-91.

26. Jaeschke R, Guyatt GH, Sackett DL: Users' guides to the medical literature. III. How to use an article about a diagnostic test. B. What are the results and will they help me in caring for my patients? The Evidence-Based Medicine Working Group. JAMA 1994; 271(9):703-7.

27. Zambon JJ, Grossi, SG, Machtei EE, Ho AW, Dunford R, Genco RJ: Cigarette smoking increases the risk for subgingival infection with periodontal pathogens. $J$ Periodontol 1996; 67 (10 Suppl): 1050-4.

28. Kamma JJ, Nakou M, Baehni PC: Clinical and microbiological characteristics of smokers with early onset periodontitis. J Periodontal Res 1999;34(1): 25-33.

29. Eggert FM, McLeod MH, Flowerdew G: Effects of smoking and treatment status on periodontal bacteria: evidence that smoking influences control of periodontal bacteria at the mucosal surface of the gingival crevice. J Periodontol 2001;72(9):1210-20.

30. Haffajee AD, Socransky SS. Relationship of cigarette smoking to the subgingival microbiota. J Clin Periodontol 2001;28(5): 377-388.

31. Shiloah J, Patters MR, Waring MB: The prevalence of pathogenic periodontal microflora in healthy young adult smokers. J Periodontol 2000;71(4):562-7.

32. Rosenberg M, Kulkarni GV, Bosy A, McCulloch CA: Reproducibility and sensitivity of oral malodor measurements with a portable sulphide monitor. J Dent Res 1991;70(11): 1436-40.

33. Rosenberg M, Septon I, Eli I, Bar-Ness R, Gelernter I, Brenner S, Gabbay J: Halitosis 
measurement by an industrial sulphide monitor. J Periodontol 1991;62(8):487-9.

34. Silwood CJ, Grootveld MC, Lynch E: A multifactorial investigation of the ability of oral health care products (OHCPs) to alleviate oral malodour. J Clinical Periodontol 2001;28(7):634-41.

35. Furne J, Majerus G, Lenton P, Springfield J, Levitt DG, Levitt MD: Comparison of volatile sulfur compound concentrations measured with a sulfide detector vs. gas chromatography. J Dent Res 2002;81(2):140-3.

\section{FIGURE LEGENDS}

Figure 1

ROC curves for identifying $P$. gingivalis in dental plaque based on VSC measurements in subjects with and without a smoking habit. Circles indicate optimal cut-off points, as shown in Table 4.

Figure 2

ROC curves for identifying $P$. intermedia in dental plaque based on VSC measurements in subjects with and without a smoking habit. Circles indicate optimal cut-off points, as shown in Table 4.

Figure 3

ROC curves for identifying $T$. denticola in dental plaque based on VSC measurements in subjects with and without a smoking habit. Circles indicate optimal cut-off points, as shown 
in Table 4. 


\section{Figure 1}

(A) Subjects with smoking habit

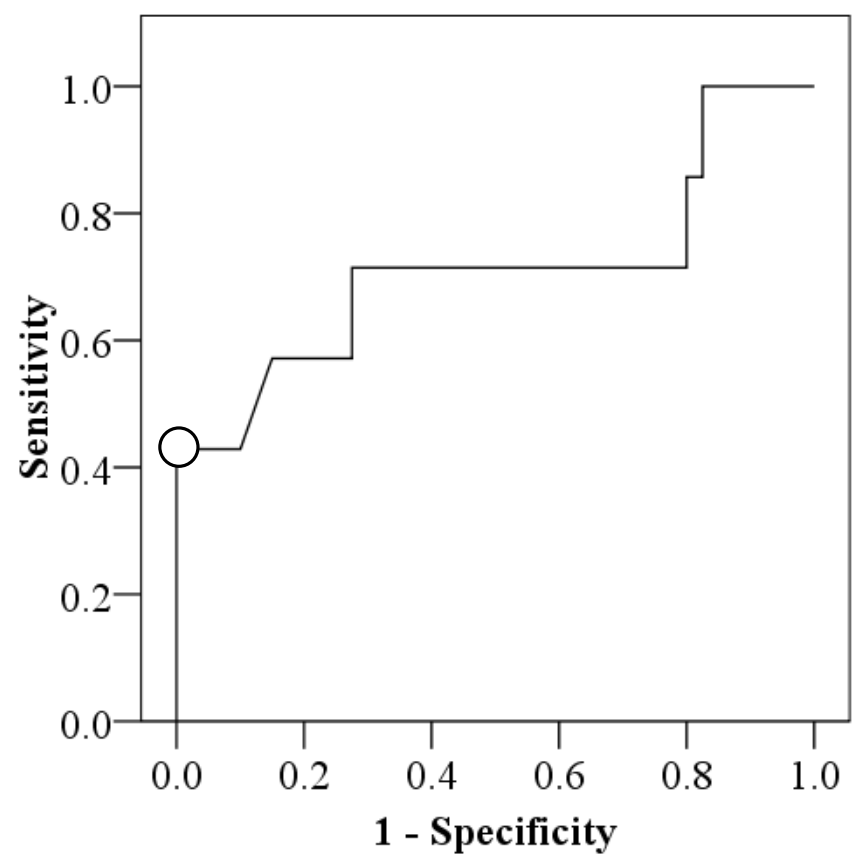

(B) Subjects without smoking habit

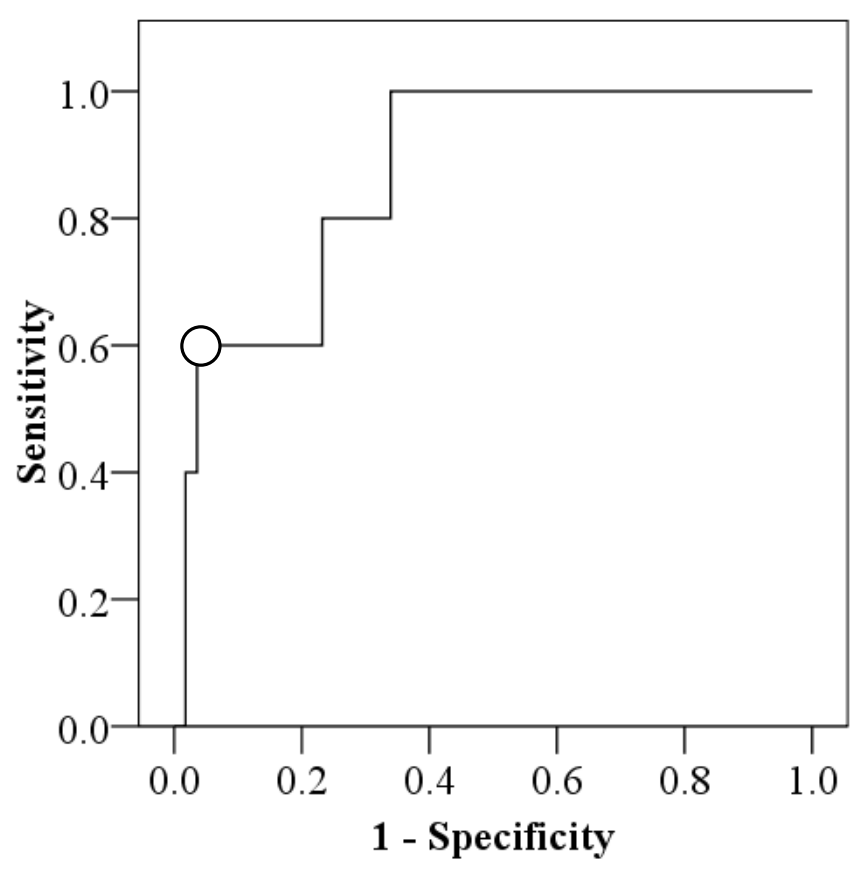

Kishi, et al. 


\section{Figure 2}

(A) Subjects with smoking habit

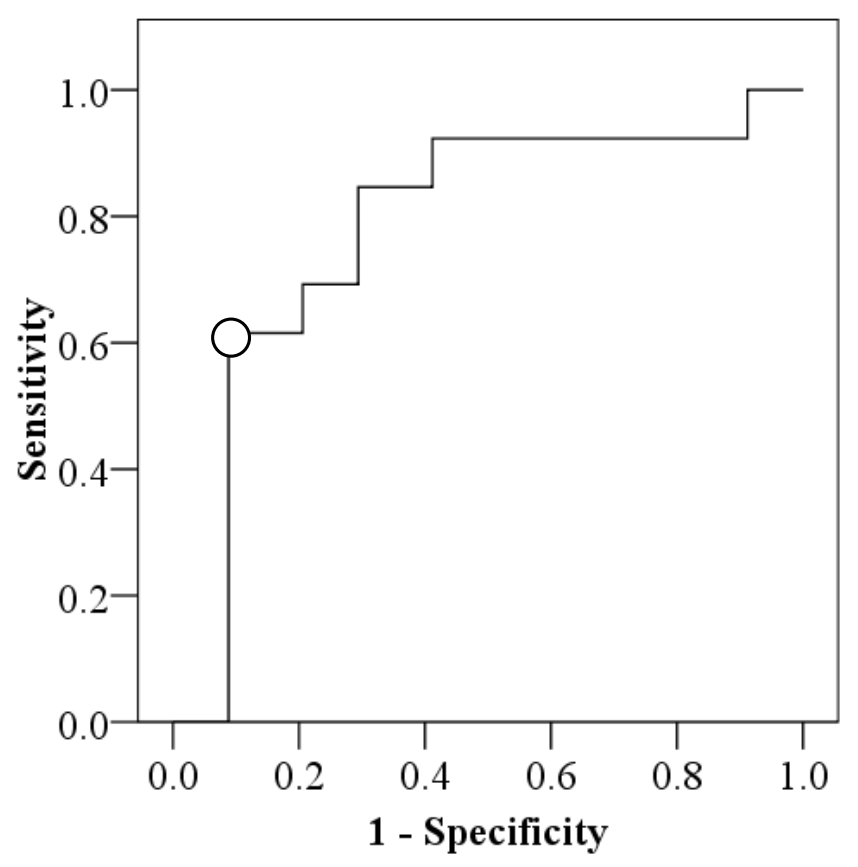

(B) Subjects without smoking habit

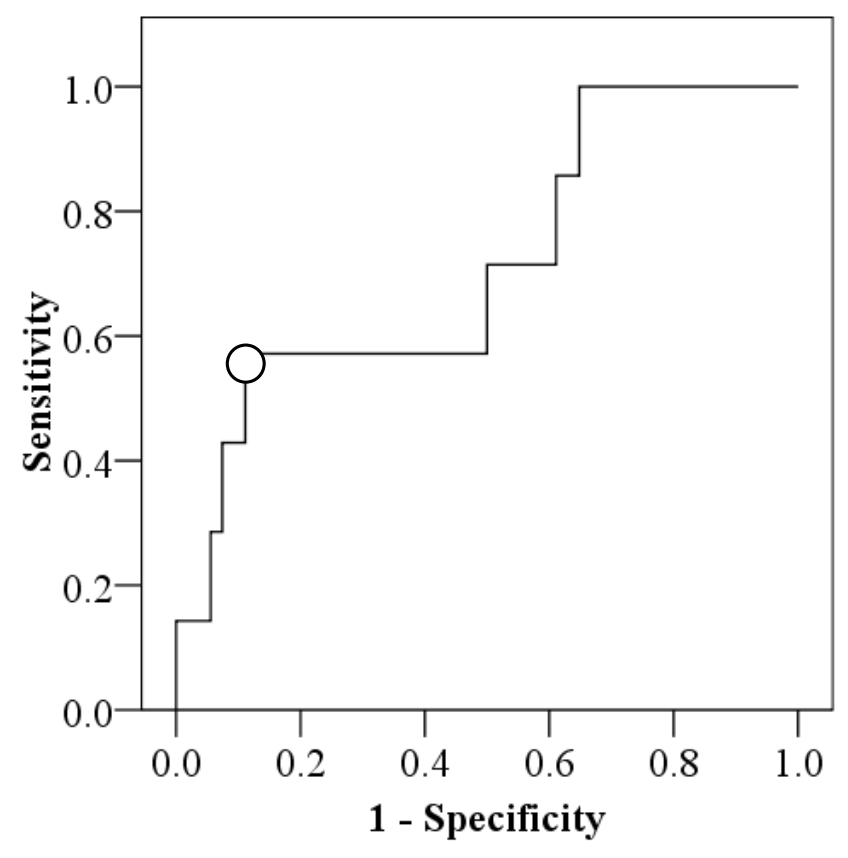

Kishi, et al. 


\section{Figure 3}

(A) Subjects with smoking habit

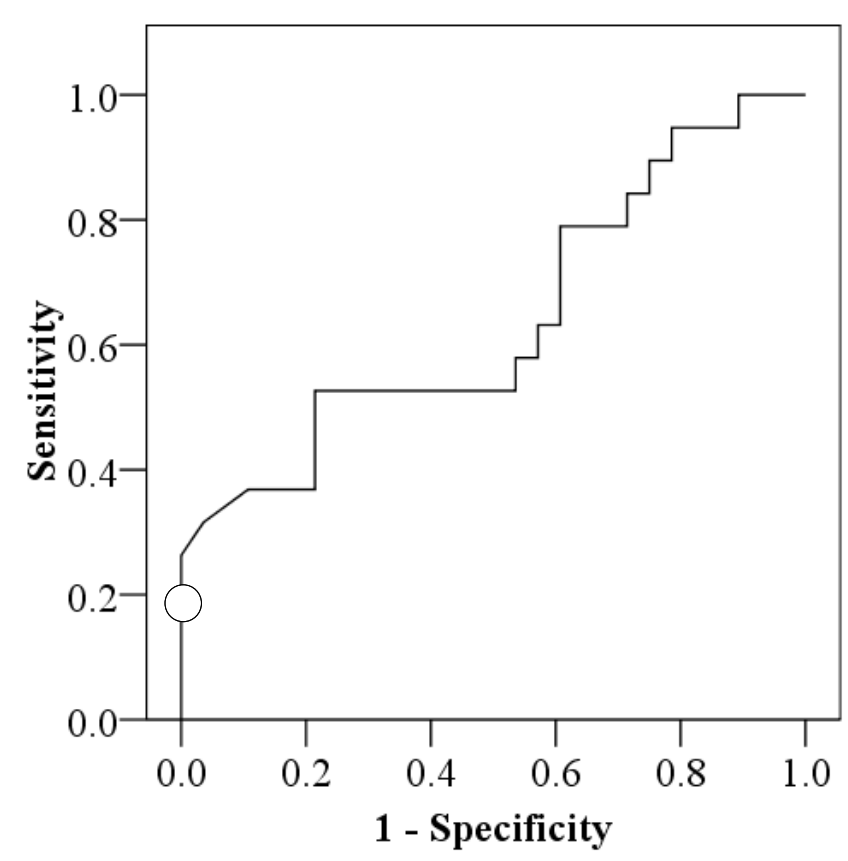

(B) Subjects without smoking habit

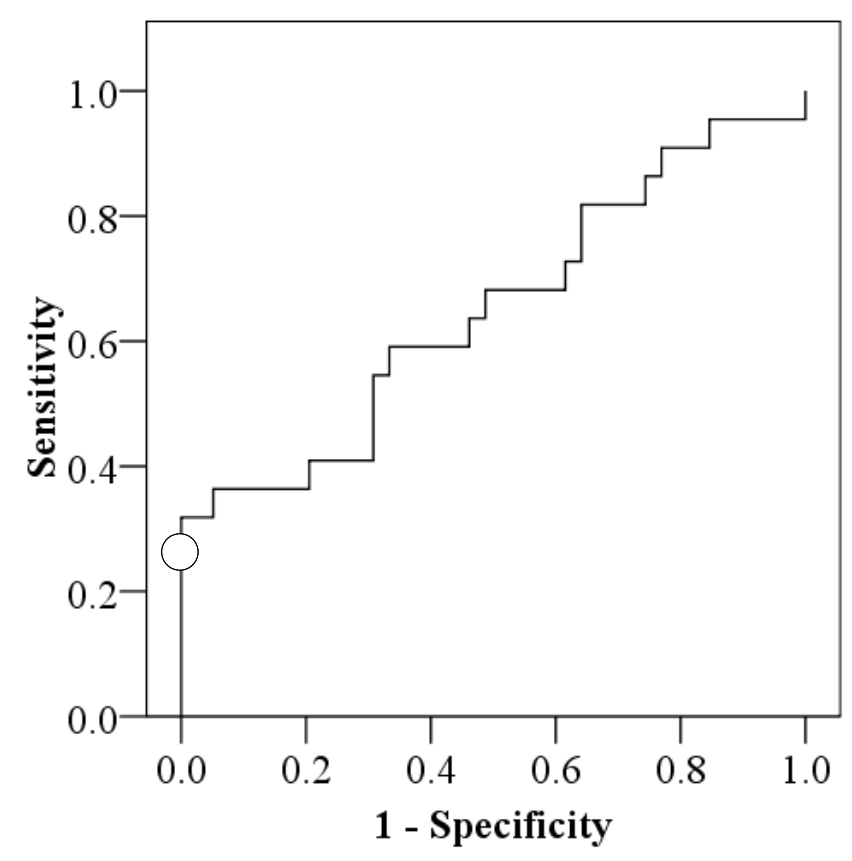

Kishi, et al. 
Table 1. Distributions of age and measurements among the subjects

\begin{tabular}{lcc}
\hline & Average \pm S.D. ${ }^{1}$ & Range \\
\hline Age in years & $23.5 \pm 2.56$ & $19-30$ \\
Salivary volume $(\mathrm{ml} / \mathrm{min})$ & $2.27 \pm 1.45$ & $0.20-9.60$ \\
Amount of tongue coating (mg) & $109 \pm 44.2$ & $42-250$ \\
VSC concentration $(\mathrm{ppb})^{2}$ & $164 \pm 124$ & $28-543$ \\
Log VSC $^{3}$ & $2.10 \pm 0.329$ & $1.46-2.74$ \\
\hline
\end{tabular}

${ }^{1}$ Standard deviation

${ }^{2}$ Halimeter measurement

${ }^{3} \log _{10}$ (VSC concentration) 
Table 2. Comparisons of results of periodontopathic bacteria detection between tongue and plaque samples

\begin{tabular}{|c|c|c|c|c|c|c|c|}
\hline & \multicolumn{3}{|c|}{ Prevalence $^{1}$} & \multirow{3}{*}{$\begin{array}{l}\text { Concordance } \\
\text { rate }^{2}\end{array}$} & \multirow[b]{3}{*}{$p$-value ${ }^{3}$} & \multirow{2}{*}{\multicolumn{2}{|c|}{$\begin{array}{l}\text { Number of positive/negative subjects } \\
\text { (\%positive) }\end{array}$}} \\
\hline & & \multicolumn{2}{|c|}{ Tongue coating } & & & & \\
\hline & & $(+)$ & $(-)$ & & & Tongue coating & Plaque \\
\hline \multirow[t]{2}{*}{ P. gingivalis } & Plaque $(+)$ & 10 & 2 & 0.870 & $<0.001$ & 22/86 (20.4) & 12/96 (11.1) \\
\hline & $(-)$ & 12 & 84 & & & & \\
\hline \multirow[t]{2}{*}{ T. forsythia } & Plaque $(+)$ & 70 & 2 & 0.787 & $<0.001$ & 91/17 (84.2) & 72/36 (66.7) \\
\hline & $(-)$ & 21 & 15 & & & & \\
\hline \multirow[t]{2}{*}{ P. intermedia } & Plaque $(+)$ & 18 & 2 & 0.704 & $<0.001$ & $48 / 60(44.4)$ & 20/90 (18.5) \\
\hline & $(-)$ & 30 & 58 & & & & \\
\hline \multirow[t]{2}{*}{ T. denticola } & Plaque $(+)$ & 11 & 30 & 0.667 & 0.027 & 17/91 (15.7) & $41 / 67(38.0)$ \\
\hline & $(-)$ & 6 & 61 & & & & \\
\hline
\end{tabular}

\footnotetext{
${ }^{1}(+)$ and $(-)$ indicate numbers of samples positive and negative for the bacterium

${ }^{2}$ Concordance rate in detection results between tongue coating and plaque samples from a single subject

${ }^{3}$ Chi-square test for independence
} 
Table 3. Selected variables in final model of multiple logistic regression analysis ${ }^{1}$

\begin{tabular}{|c|c|c|c|c|c|c|c|c|}
\hline \multirow[b]{2}{*}{ Species } & \multicolumn{4}{|c|}{ Tongue coating } & \multicolumn{4}{|c|}{ Dental plaque } \\
\hline & Selected variable & $\operatorname{Exp}(B)^{2}$ & $95 \% \mathrm{CI}^{3}$ & $p$-value & Selected variable & $\operatorname{Exp}(B)^{2}$ & $95 \% \mathrm{CI}^{3}$ & $p$-value \\
\hline \multirow[t]{2}{*}{ P. gingivalis } & Smoking habit & 4.67 & $1.26-17.3$ & 0.021 & Smoking habit & 6.19 & $1.24-30.9$ & 0.026 \\
\hline & Log VSC & 221 & $15.1-3227$ & $<0.001$ & Log VSC & 135 & $5.41-3374$ & 0.003 \\
\hline \multirow[t]{2}{*}{ T. forsythia } & Smoking habit & 5.78 & $1.49-22.4$ & 0.011 & \multirow[t]{2}{*}{ No variable was selected } & & & \\
\hline & Log VSC & 7.54 & $1.36-41.9$ & 0.021 & & & & \\
\hline \multirow[t]{3}{*}{ P. intermedia } & \multirow[t]{3}{*}{$\begin{array}{l}\text { Amount of tongue } \\
\text { coating }\end{array}$} & \multirow[t]{3}{*}{1.01} & \multirow[t]{3}{*}{$1.00-1.02$} & \multirow[t]{3}{*}{0.012} & $\begin{array}{c}\text { Amount of tongue } \\
\text { coating }\end{array}$ & 0.985 & $0.969-1.001$ & 0.068 \\
\hline & & & & & Smoking habit & 8.92 & $2.41-33.0$ & 0.001 \\
\hline & & & & & Log VSC & 35.4 & $4.07-307$ & 0.001 \\
\hline \multirow[t]{3}{*}{ T. denticola } & \multirow{3}{*}{\multicolumn{2}{|c|}{ No variable was selected }} & & & $\begin{array}{l}\text { Amount of tongue } \\
\text { coating }\end{array}$ & 0.985 & $0.973-0.997$ & 0.017 \\
\hline & & & & & Smoking habit ${ }^{4}$ & 2.53 & $0.997-6.43$ & 0.051 \\
\hline & & & & & Log VSC & 10.4 & $2.45-44.5$ & 0.002 \\
\hline
\end{tabular}

\footnotetext{
${ }^{1}$ Independent variables at the first step were gender (female: 0 , male: 1 ), smoking habit (non-smoker: 0 , current smoker: 1 ), amount of tongue coating (mg), salivary volume ( $\mathrm{ml} / \mathrm{min}$ ), number of DMFT (total number of decayed, filled and missing teeth), and logVSC
}

${ }^{2}$ Adjusted partial regression coefficient

${ }^{3} 95 \%$ confidence interval 
Table 4. Indices of effectiveness of screening test at optimal cut-off values on ROC curves ${ }^{1}$

\begin{tabular}{|c|c|c|c|c|c|c|c|c|c|}
\hline \multirow{2}{*}{ Species } & \multirow{2}{*}{$\begin{array}{c}\text { Smoking } \\
\text { habit }\end{array}$} & \multicolumn{2}{|c|}{ Cut-off value } & \multirow{2}{*}{ Sensitivity } & \multirow{2}{*}{ Specificity } & \multirow{2}{*}{$\operatorname{LR}(+)^{2}$} & \multirow{2}{*}{$\operatorname{LR}(-)^{3}$} & \multirow{2}{*}{$\begin{array}{c}\text { Pre-test } \\
\text { probabilty }^{4}\end{array}$} & \multirow{2}{*}{$\begin{array}{l}\text { Post-test } \\
\text { probability }\end{array}$} \\
\hline & & Log VSC & VSC (ppb) & & & & & & \\
\hline \multirow{3}{*}{ P. gingivalis } & & & & 0.429 & 0.975 & & & 0.149 & 0.750 \\
\hline & $(+)$ & 2.36 & 230 & $(3 / 7)$ & $(39 / 40)$ & 17.1 & 1.71 & $(7 / 47)$ & $(3 / 4)$ \\
\hline & $(-)$ & 2.65 & 442 & $\begin{array}{r}0.600 \\
(3 / 5)\end{array}$ & $\begin{array}{c}0.964 \\
(54 / 56)\end{array}$ & 16.8 & 2.41 & $\begin{array}{l}0.082 \\
(5 / 61)\end{array}$ & $\begin{array}{l}0.600 \\
(3 / 5)\end{array}$ \\
\hline \multirow{4}{*}{ P. intermedia } & $(+)$ & 221 & 161 & 0.615 & 0.912 & 607 & 234 & 0.277 & 0.727 \\
\hline & (T) & 2.21 & 101 & $(8 / 13)$ & $(31 / 34)$ & 0.51 & 2.04 & $(13 / 47)$ & $(8 / 11)$ \\
\hline & $(-)$ & 258 & 383 & 0.571 & 0.889 & 5.14 & 207 & 0.115 & 0.400 \\
\hline & 11 & 2.00 & 50 & $(4 / 7)$ & $(48 / 54)$ & .14 & & $(7 / 61)$ & $(4 / 10)$ \\
\hline \multirow{4}{*}{ T. denticola } & $(+)$ & 228 & 188 & 0.315 & 0.946 & 884 & 141 & 0.404 & 0.857 \\
\hline & 17 & 2.20 & 100 & $(6 / 19)$ & $(27 / 28)$ & 4.04 & 1.41 & $(19 / 47)$ & $(6 / 7)$ \\
\hline & $(-)$ & 254 & 349 & 0.364 & 0.949 & 709 & 149 & 0.163 & 0.800 \\
\hline & (-) & 2.04 & 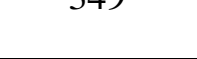 & $(8 / 22)$ & $(37 / 39)$ & 1.00 & 1.43 & $(10 / 61)$ & $(8 / 10)$ \\
\hline
\end{tabular}

${ }^{1}$ Cut-off values correspond with circles in Figures 1, 2, and 3

${ }^{2}$ Likelihood ratios for positive test: sensitivity / (1 - specificity)

${ }^{3}$ Likelihood ratios for negative test: specificity/ (1 - sensitivity)

${ }^{4}$ Pre-test probability of prevalence of bacterium in subjects with or without smoking habit 